\title{
Avaliação de Cargos: O Método de Orçamento
}

\section{Tomás de Vilanova Monteiro Lopes}

A avaliação de cargos, tão necessária à manutenção de equilibrio entre o custo da mão de obra e salário justo e compensador, é estudado no presente trabalho de TOMÁs DE VILANOVA MONTEIRO LOPES.

O método de avaliação, conhecido como ordemento, é o que serve de base ao estudo do autor, que o classifica de subjetivo e inseguro, já que o cargo é avaliado no seu aspecto global, segundo a opinião que dêle tem o avaliador, sem o uso de pacirōes de comparação.

Apesar dessa opinião, o autor reconhece aspectos benéficos na maneira de avaliação de cargos pelo método de ordenamento, entre as quais a rapidez de sua execução e o baixo prêço de custo.

U

\section{CONCEITO}

MA das necessidades básicas do empregador é a mão-de-obra econômica; uma das necessidades básicas do empregado é o salário-compensador.

O ponto de equilibrio entre essas duas necessidades é o salário justo, ou seja aquêle tipo de remuneração que permita ao empregador receber do empregado trabalho de categoria correspondente ao nivel do salário que paga; e assegure do empregado a percepção de salário correspondente à categoria do trabalho que presta.

Quando o salário que o empregado recebe está acima da categoria do trabalho prestado, a mão-de-obra deixa de ser econômica e, portanto, uma das necessidades básicas do empregador não é satisfeita. Mas não é só. Como o salário é um componente do preço de custo e êste elemento base do preço de venda, a coletividade, representada pelos consumidores, paga pelo que consome mais do que deve pagar, quando os salários são fixados acima do nível justo. Por outro lado, quando está abaixo da categoria do trabalho prestado, o salário não é compensador e, conseqüentemente, fica desatendida uma das necessidades básicas
do mpregado. 
O salário abaixo do nivel justo prejudica o recrutamento e, por consequiência, a seleção do pessoal: tem efeitos corrosivos sôbre o moral do grupo e constitui uma das causas mais eficientes da instabilidade da mão-de-obra.

Essas razões bastam para demonstrar o quanto é importante, em administração de pessoal, o problema da avaliação de cargos.

Podemos conceituar essa avaliação como sendo o processo através do qual estabelecemos a posição dos vários cargos numa escala de hierarquia apropriada e, em face dessa posição, determinamos o salário que deve ser atribuído a cada um.

Similar a êsse conceito é o proposto pelo Occupational Analysis Branch, do U.S. Employmente Service:

"Avaliação do trabalho é a operação completa de fixação do valor que determinado trabalho tem dentro de uma organização. relativamente aos demais trabalhos que nesta última existem". (1)

Dêsses dois conceitos é fácil deduzir que a avaliação de cargos, além de proporcionar uma base racional para o problema da fixação dos salários, constitui, ainda, um instrumento de organização de múltiplas utilidades. A extensa gama de questões liga. das à distinção dos niveis de autoridade e responsabilidade, aí compreendidas as idéias de chefia, promoção, treinamento etc., tem na avaliação de cargos uma boa fonte de auxilio e sugestões.

\section{A AVALIAÇÃO POR ORDENAMENTO}

A avaliação por ordenamento considera o cargo no seu aspecto global, conforme a opinião que dêle tem o avaliador. Não usa um padrão externo e uniforme, com o qual os cargos possam ser confrontados. E' um método muito subjetivo e a avaliação que produz deixa a desejar, mesmo quando os avaliadores têm grande experiência na utilização do método e seguro conhecimento dos cargos a avaliar. Ademais, é de aplicação limitada, uma vez que seu emprêgo se torna pràticamente inviável quando a avalia. ção deve abranger um número de cargos elevado. Oferece, entretanto, como atrativo o seu preço de custo, que é baixo, e a rapidez de execução. BENGE, BurK e $\mathrm{H}_{\mathrm{AY}}$ (2) que não ocultam sua simpatia pelo método de ordenamento, afirmam que os resultados que êle pode proporcionar coincidem em cêrca de $60 \%$ com os resultados obtidos com o emprêgo de outros métodos mais requintados.

A primeira etapa na prática da avaliação por ordenamento consiste na designação dos avaliadores. Estes, geralmente em número de três, devem ser pessoas muito bem familiarizadas com

(1) Apud E. Lanham - Job Evaluation - Mc Graw Hill Boos Company Inc. - New Yory, 1955.

(2) Manual of Job Evaluation - Harpers Brothers, New York, 1941. 
os objetivos, organização e funcionamento da instituição a que pertencem os cargos e, naturalmente, dotadas da capacidade de critica e de julgamento indispensável à boa utilização do método. As pessoas que não disponham de um conhecimento pormenorizado da instituição, difícilmente poderão determinar o que para esta significam, em realidade, os diferentes conjuntos de atribuições e provàvelmente se deixarão impressionar por aspectos de importância secundária. Em tal caso a subjetividade do método será agravada pela errônea concepção em que o avaliador basear o seu trabalho.

Designado os avaliadores, procede-se à seleção dos cargos típicos (dez no mínimo e vinte e cinco no máximo), salvo se os cargos existentes fôrem em número reduzido ou suscetiveis de agrupamento em categorias poucas e homogêneas (grande númıro de cargos e pequeno número de espécies), caso em que poderemos tomar de saída a totalidade dos cargos. Convém, antes de prosseguir, esclarecermos que cargos típicos são aquêles que constituem uma amostra representativa da instituição, ou seja aquêles que, pela natureza do trabalho que lhes corresponde, dão uma idéia da instituição, permitindo caracterizar esta última como oryaporte etc. Devem êles cobrir todos os niveis de dificuldde e responsabilidade funcionais existentes na instituição, desde os mais
elementares aos mais elevados, e terem suas atribuições fixadas de modo tal que em relação a elas não haja controvérsia.

As denominações de cargos típicos, às vezes acompanhadas de uma descrição sumária de cada um, são registradas numa fôlha de papel com tantas cópias quantos forem os avaliadores. Cała um dêstes, de posse de sua cópia da fôlha de registro, indicará numa fôlha à parte a ordem em que os mesmo cargos devem ser colocados, conforme sua importância crescente.

A fôlha de registro e as respectivas cópias podem ser substituidas por coleções de cartões, de sorte que cada avaliadur, que, a seu ver, cabe a cada cargo na ordem de importância. Convencionada a ordem de importância crescente, o cartão currespondente ao cargo menos importante virá em primeiro lugar; entre êsses dois extremos serão colocado, em último lugar; e nientes os cartões relativos serão colocados nas posições converam-se os cartões, na ordem em que cargos. Feito isso, nuneliadores. O número que cada que foram arrumados pelos avade avaliação do cargo correspondente.

cado em 1\% lugar receberá e importância crescente, o cargo colograu 2 , e assim por diante. Um pequenocado em 2 lugar receberá 
as diferentes fases do processo de ordenamento. Figuremos, pois, que numa determinada instituição foram selecionados como tlpicos os cargos indicados abaixo:

\section{CARGOS TÍPICOS}

TABELA 1

\section{DENOMINAÇÃO}

Monitor

Professor
DESCRIÇÃO SUM ÁRIA

Distribuir o material didático aos alunos; recolhê-lo ao fim das aulas e guardá-lo sob sua inteira responsabilidade.

Ministrar aulas, de acôrdo com os programas aprovados.

Como no caso os avaliadores seriam três, começariamos por preparar três coleções iguais, de dez cartões; e como cada coleção deveria abranger todos os cargos por avaliar, seriam feitos três cartões iguais para o cargo $A$, três para o cargo $B$ e assim sucessivamente. Dariamos uma coleção a cada avaliador, a fim de que êste arrumasse os cartões na ordem crescente da importância dos cargos por êles representados. Em seguida numeraríamos os cartões e teríamos os resultados da avaliação. Tais resultados poderiam ser apresentados sob a forma de uma tabela como esta:

Escrevente-Datilógrafo

Orientador

Ausiliar de Ensino

Coordenador.

Instrutor

Correntista

Pagador

Zelador
Datilografar as súmulas de aulas.

Organizar os programas pelos quais deyerão reger-se as aulas e orientar os professôres na aplicação dos métodos didáticos mais apropriados ao ensino da matéria de tais programas.

Apurar a frequência dos alunos.

Organizar os planos de cursos; fixar as diretrizes a serem obedecidas na organização dos programas, visando à melhor integração dêstes últimos naqueles planos.

Realizar, sob a orientação do professor, as demonstrações e exercícios práticos que complementem as aulas ministradas.

Organizar as fôlhas de pagamento dos professôres auxiliares e encaminhá-las à Tesouraria.

Efetuar o pagamento do pessoal e dos fornecedores.

Executar os trabalhos de limpeza e arrumacão dos locais de trabalho. 
A tapela mostra que houve divergência na avaliação dos cargos de Monitor, Zelador, Correntista e Pagador. Na prática, divergências dèsse tipo são bastante comuns; para eliminá-las os avaliadores trocam idéias entre si, reexaminam seus pontos devista, debatem os critérios adotados e tentam chegar a um acôrdo. Este é quase sempre possivel, uma vez que raramente as causas das divergências são de molde a criar posições irredutíveis. Além disso, como a avaliação é repetida por duas ou mais vêzes, aquelas divergências, não raro, pràticamente se anulam nas médias dos graus das diferentes avaliações. Só excepcionalmente não é possivel conciliar se a discrepância de julgamento entre os avaliadores e nesse caso o cargo que der lugar a tal desacôrdo deve ser retirado da lista dos cargos típicos.

Avaliados os cargos típicos procede-se à avaliação dos demais cargos, pelo mesmo processo aqui descrito, confrontandorse os cargos típicos já avaliados com os cargos que se deseja avaliar e decidindo-se quanto à posição em que êste último será colocado. Para efeito de confronto, toma $-s e$, em cada caso, o cargo típico que, pelas suas atribuições, maior semelhança ou afinidade tiver
com o cargo a ser avaliado.

Também aqui se fazem, comumente, três avaliações com intervalos de dez ou quinze dias, e toma-se com expressão numérica do julgamento de cada avaliador a média dos graus por êle atri-
buridos ao cargo nas diferentes avaliações.

A média dessas médias será o grau final que expressa a avaliação do cargo.

Todo êsse trabalho será feito primeiramente com os cargos típicos. A avaliação dos demais cargos far-se-á em seguida por comparação de cada um dêstes com o cargo típico mais seme-
lhante.

\begin{tabular}{|c|c|c|c|c|c|}
\hline \multicolumn{2}{|c|}{ 1. AVALIADOR } & \multicolumn{2}{|c|}{ 2." AVALIADOR } & \multicolumn{2}{|c|}{ 3." AVALIADOR } \\
\hline CARGO & AVALIAÇÃO & CARGO & M/IU: & CARGO & AVALIAÇÃOO \\
\hline $\begin{array}{l}\text { Monitor............ } \\
\text { Zelador............. } \\
\text { Auxiliar de Ensino. } \\
\text { Escrevente-Datil... }\end{array}$ & $\begin{array}{l}1 \\
2 \\
3 \\
4 \\
\end{array}$ & $\begin{array}{l}\text { Zelador........... } \\
\text { Monitor........... } \\
\text { Auxiliar de Fnsino } \\
\text { Escrevente-Datil.. }\end{array}$ & $\begin{array}{l}1 \\
2 \\
3 \\
4\end{array}$ & $\begin{array}{l}\text { Monitor........... } \\
\text { Zelador.......... } \\
\text { Auxiliar de Ensino } \\
\text { Escrevente-Datil.. } \\
\end{array}$ & $\begin{array}{l}1 \\
2 \\
3 \\
4\end{array}$ \\
\hline $\begin{array}{l}\text { Correntista......... } \\
\text { Pagador........... } \\
\text { Instrutor.......... } \\
\text { Professor.......... } \\
\text { Orientador......... } \\
\text { Coordenador....... }\end{array}$ & $\begin{array}{r}5 \\
6 \\
7 \\
8 \\
9 \\
10\end{array}$ & $\begin{array}{l}\text { Pagador........... } \\
\text { Correntista........ } \\
\text { Instrutor......... } \\
\text { Professor.......... } \\
\text { Orientador........ } \\
\text { Coordenador...... }\end{array}$ & $\begin{array}{r}5 \\
6 \\
7 \\
8 \\
9 \\
10\end{array}$ & $\begin{array}{l}\text { Pagador........... } \\
\text { Correntista........ } \\
\text { Instrutor.......... } \\
\text { Professor.......... } \\
\text { Orientador........ } \\
\text { Coordenador.. . . }\end{array}$ & $\begin{array}{r}5 \\
6 \\
7 \\
8 \\
9 \\
10\end{array}$ \\
\hline
\end{tabular}


A versão do método de ordenamento que acabamos de apresentar é a mais divulgada. Não é, porém a única. Há uma outra forma de avaliação por ordenamento que importa em tomar os cargos dois a dois, para efeito de comparação. Conhecida sob o título de método de comparação por pares (Method of Paired Comparison) eia. como a forma anteriormente exposta reclama o mesmo trabalho preliminar de especificação do trabalho, designação de avaliadores competentes e seleção dos cargos tipicos. A diferença está em que êstes são distribuidos em diversos pares, tantos quantos forem necessários para que cada cargo típico possa figurar ao lado de todos os outros, afim de ser confrontado com cada um dêles. Em cada par os avaliadores terão, simplesmente, que assinalar o cargo que lhes parecer mais importante. Depois disso bastará contarmos o número de vêzes em que determinado cargo foi considerado mais importante do que os que com êle foram comparados. Esse número acrescido de mais 1, representará seu grau na avaliação.

Retomemos, para efeito de ilustração o exemplo de que nos servimos anteriormente. Com os cargos típicos formulariamos os ceguintes pares:

Os pares acima foram distribuidos irregularmente de propósito, para evitar que sua apresentação numa determinada ordem viesse a constituir um elemento de possivel sugestão. As letras sublinhadas $\mathrm{F}$ ( 9 vêzes), B ( 7 vêzes) e C (3 vêzes) mostram servimos anteriormente. Com os cargos tipicos formariamos os seguintes resultados.

Graus

$$
\begin{aligned}
& 10-\mathrm{F} \\
& 9 \ldots \\
& 8-\mathrm{B} \\
& 7 \ldots \\
& 6 \ldots \\
& 5 \ldots \\
& 4-\mathrm{C} \\
& 3 \ldots \\
& 2 \ldots \\
& 1 \ldots
\end{aligned}
$$

Pelo mesmo processo prosseguiriamos na avaliação dos demais cargos, atế que fôssem preenchidas tôdas as posições da escola.

$\mathrm{O}$ ordenamento através da comparação por pares torna a avaliação mais cômoda, por isso que os avaliadores, para emitir seu julgamento, lidam apenas com dois cargos de cada vez, não precisando preocupar-se com os restantes. Como, em princípio 


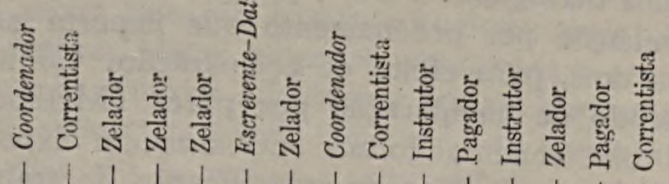

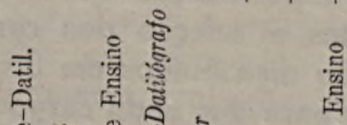

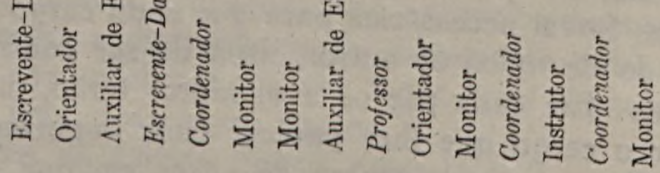

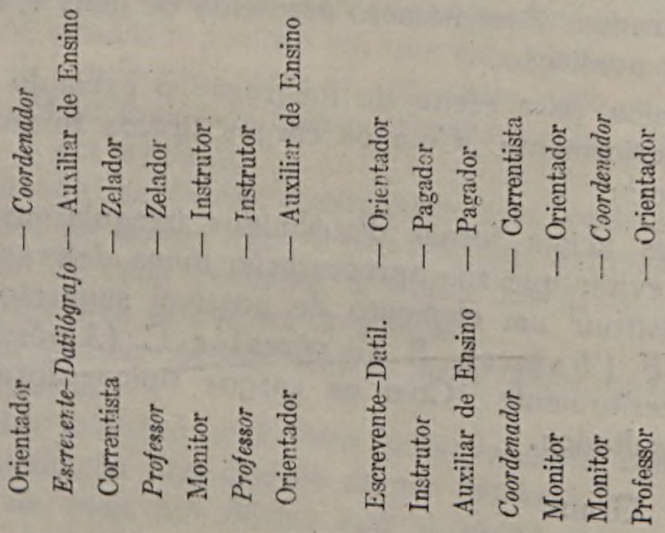

苟 竞 章

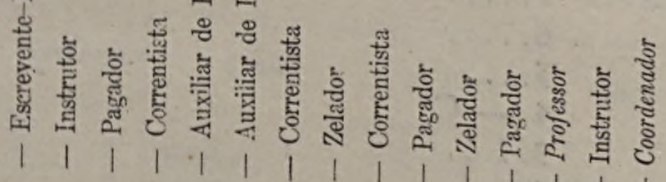

营

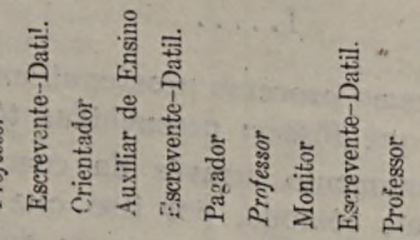


é mais fácil decidir qual a mais importante entre duas cousas do que aferir as diferenças de valores entre várias cousas, pode-se esperar que o emprêgo da comparação por pares proporcione um ordenamento melhor.

O processo de avaliação por ordenamento não atendia às necessidades das grandes emprêsas. Estas, entretanto, passaram a predominar à medida que o industrialismo foi evoluindo. Para satisfazê-las, novos processos de avaliação de cargos apareceram e dentre êles merecem destaque a avaliação por agrupamento em classe, por fatôres e por pontos.

Seria, talvez, mais acertado dizer que o processo de ordenamento se foi progressivamente apurando, mediante a substituição de um critério por outro mais aperfeiçoado, já que, em realidade, - agrupamento em classe, a discriminação e a ponderação de fatôres nada mais são do que simples critérios de ordenamento dos cargos. Ėste último é o resultado final a que visamos quando grupamos os cargos consoante os níveis de dificuldade e responsabilidades das respectivas atribuições, ou quando identificamos os fatôres dos quais depende o bom desempenho de tais atribuições e lhes conferimos certo valor, conforme a importância com que cada um concorre para aquêle desempenho.

Consolidou-se, porém, a prática de considerar o agrupamento em classe e a fonderação de fatôres como dois processos de avaliação independentes, e não como formas evoluídas do processo de ordenamento. 